\title{
A Hothouse of Great, Green Ideas
}

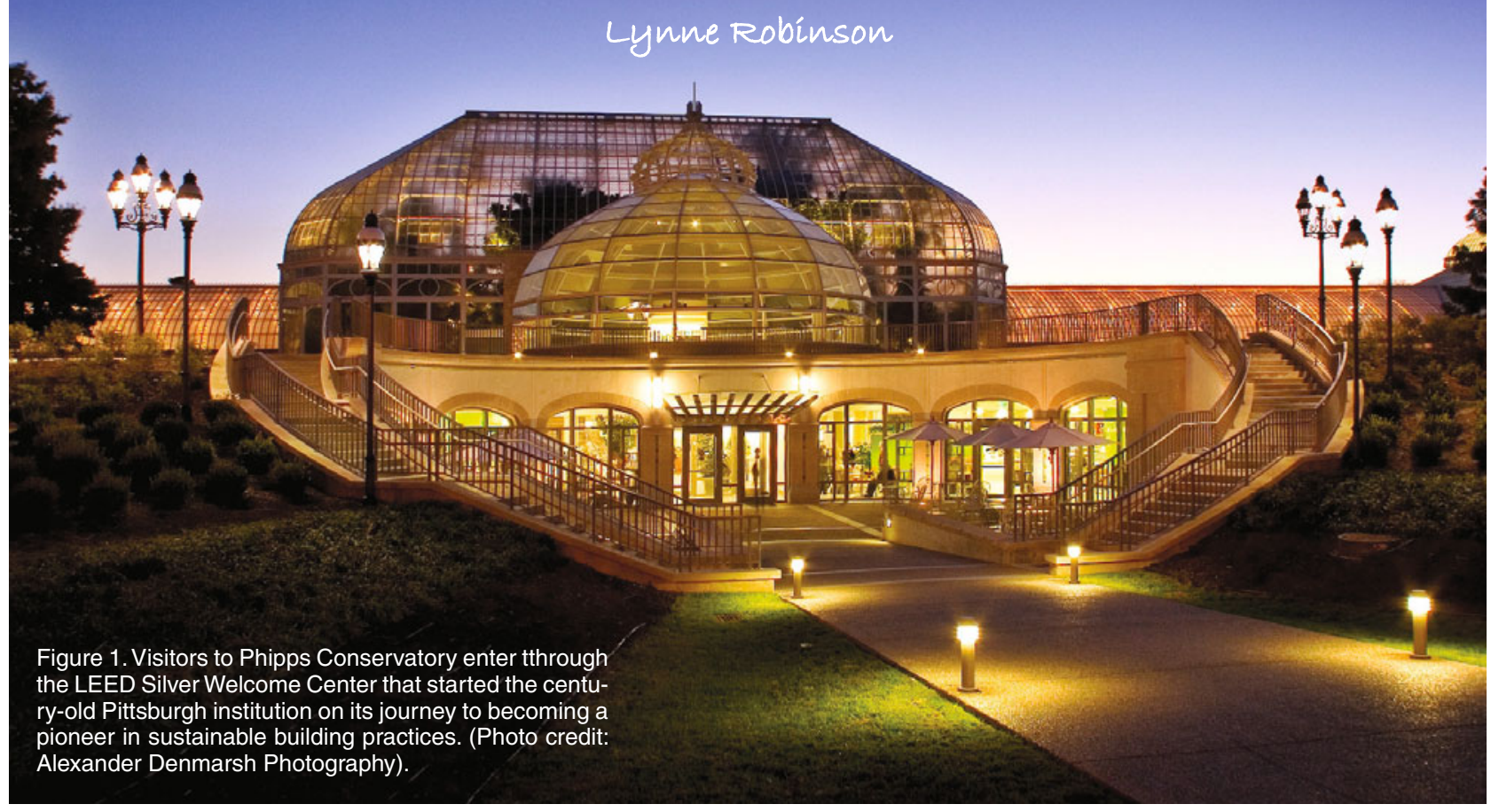

The tile was the turning point for Richard Piacentini.

The new Welcome Center at Phipps Conservatory and Botanical Gardens, Pittsburgh, Pennsylvania, was steadily progressing on its way to becoming the first LEED ${ }^{\circledR}$ (Leadership in Energy

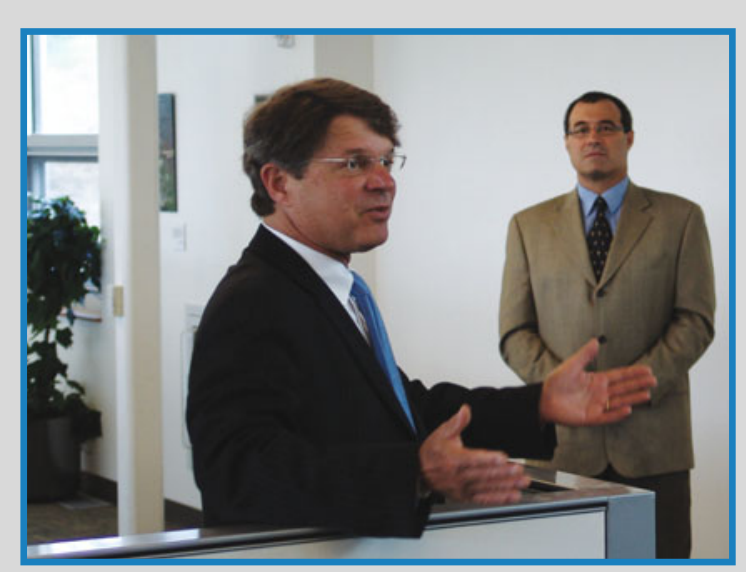

and Environmental Design)-certified visitor center in a public garden in the United States (Figure 1). Piacentini, who had made achieving the certification a priority as Phipps's executive director (Figure 2), was walking through the construction site when he noticed
Figure 2. Richard Piacentini, Phipps executive director (left foreground): "Phipps is about educating people about the environment and their relationship with the natural world. It made sense that our buildings should reflect our values." that the boxes containing interior tiles for the building had been shipped from Turkey. Knowing the certification process required that materials be manufactured regionally, Piacentini contacted his project managers to find out why tiles from half a world away were being installed. "I was told that it was $\mathrm{OK}$, that we had already gotten those points," he recalled. "My reaction was that we weren't building this building for points, and that this was about more than the certification."

In less than a decade since that incident, Phipps has made it a guiding principle to not just do less harm to the environment, but to try to heal it through sustainable practices in nearly every aspect of its operations. "The experience of designing a LEEDcertified structure set us on a whole new path of looking at everything we do and the smartest way of doing it," 
said Piacentini. "Phipps is about educating people about the environment and their relationship with the natural world. It made sense that our buildings should reflect our values."

The Welcome Center, opened in 2005, was the first milestone in a three-phase expansion project that Phipps has undertaken on the road to becoming a national tourist attraction. The final piece, the Center for Sustainable Landscapes (CSL), culminates everything that the Phipps team has learned on that journey about designing, constructing, and maintaining a sustainable building. Opened for business in summer 2012, the CSL stands a good chance of being the first building in the world to achieve the three most stringent "green" standards for the built environment: the Living Building Challenge; LEED Platinum, and the Sustainable Sites Initiative (SITES TM) Certification. Much of that success has depended on approaching materials selection and use as part of an integrative, systems-driven process.

\section{A GREEN SPOT IN THE INDUSTRIAL REVOLUTION}

The original Phipps Conservatory building was gifted to the City of Pittsburgh in 1893 by Henry Phipps, who had made his fortune as Andrew Carnegie's business partner in Carnegie Steel. A whimsical, Victorianstyled glass palace glinting in the cen-

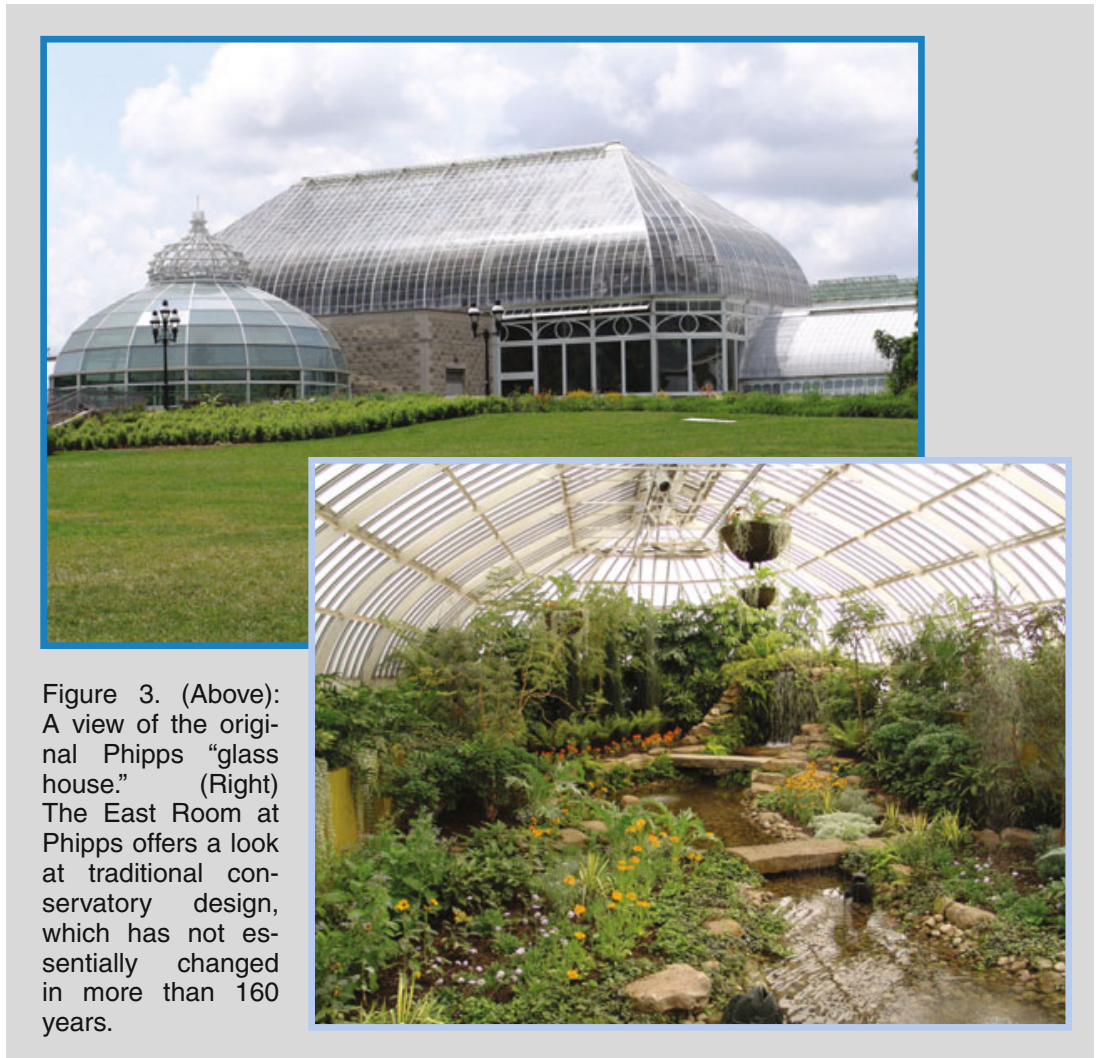

ter of one of the most heavily industrialized cities on the planet, Phipps gave many western Pennsylvania residents their first and only glimpse into exotic and tropical natural worlds (Figure 3). A South Conservatory, also a gift from Phipps, was added to the original nine-room structure between 1896 and 1897, and subsequent years brought a series of upgrades, repairs, and additions. Lining up to see a new "flower show" display at Phipps became a permanent part of Pittsburgh's collective memory, with the building's 1976 placement on the National Register of Historic Places helping to ensure that it had a spot in the future, as well.

\section{A MATERIALS SNAPSHOT OF THE CSL}

The source, manufacture, composition, and use of materials factored into almost every decision related to the design and construction of the Center for Sustainable Landscapes (CSL). A few key statistics include:

- Salvaged materials comprise 10 percent of everything used to build the facility. This includes siding made from deconstructed western Pennsylvania barns.

- Recycled materials, including structural steel and aluminum, account for 30 percent of those used onsite.

- More than 80 percent of the materials required to develop the building and landscape, including concrete, steel, and glass, were manufactured, harvested, or extracted within a 500-mile radius of Pittsburgh.

- All materials were sourced in compliance with the Living Building Challenge Materials Red List, which identifies toxic substances typically found in manufactured products.

For additional information and statistics on the CSL, go to phipps.conservatory.org/project-green-heart.

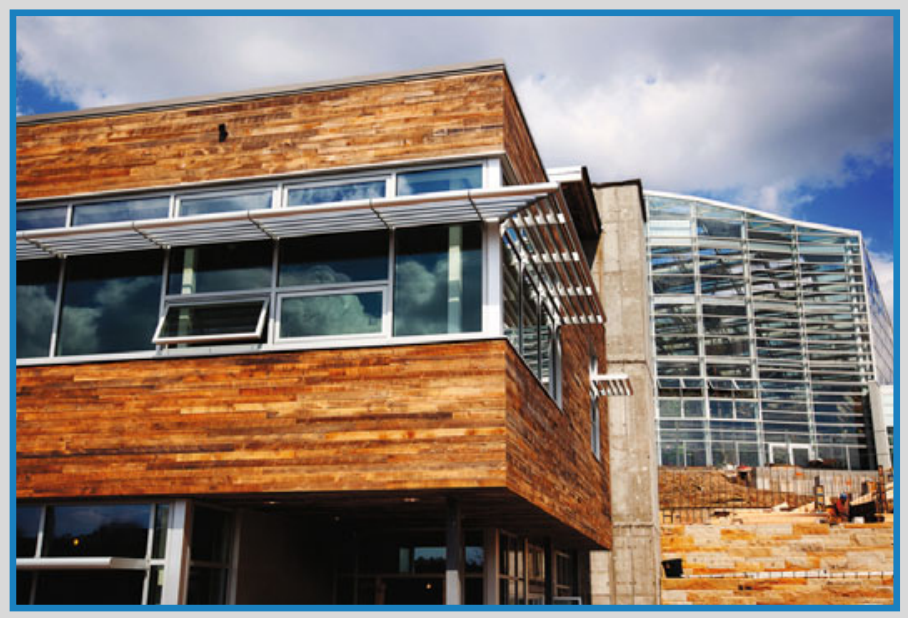

The Center for Sustainable Landscapes exterior, clad in siding made from repurposed barn wood. (Photo credit: Alexander Denmarsh Photography.) 


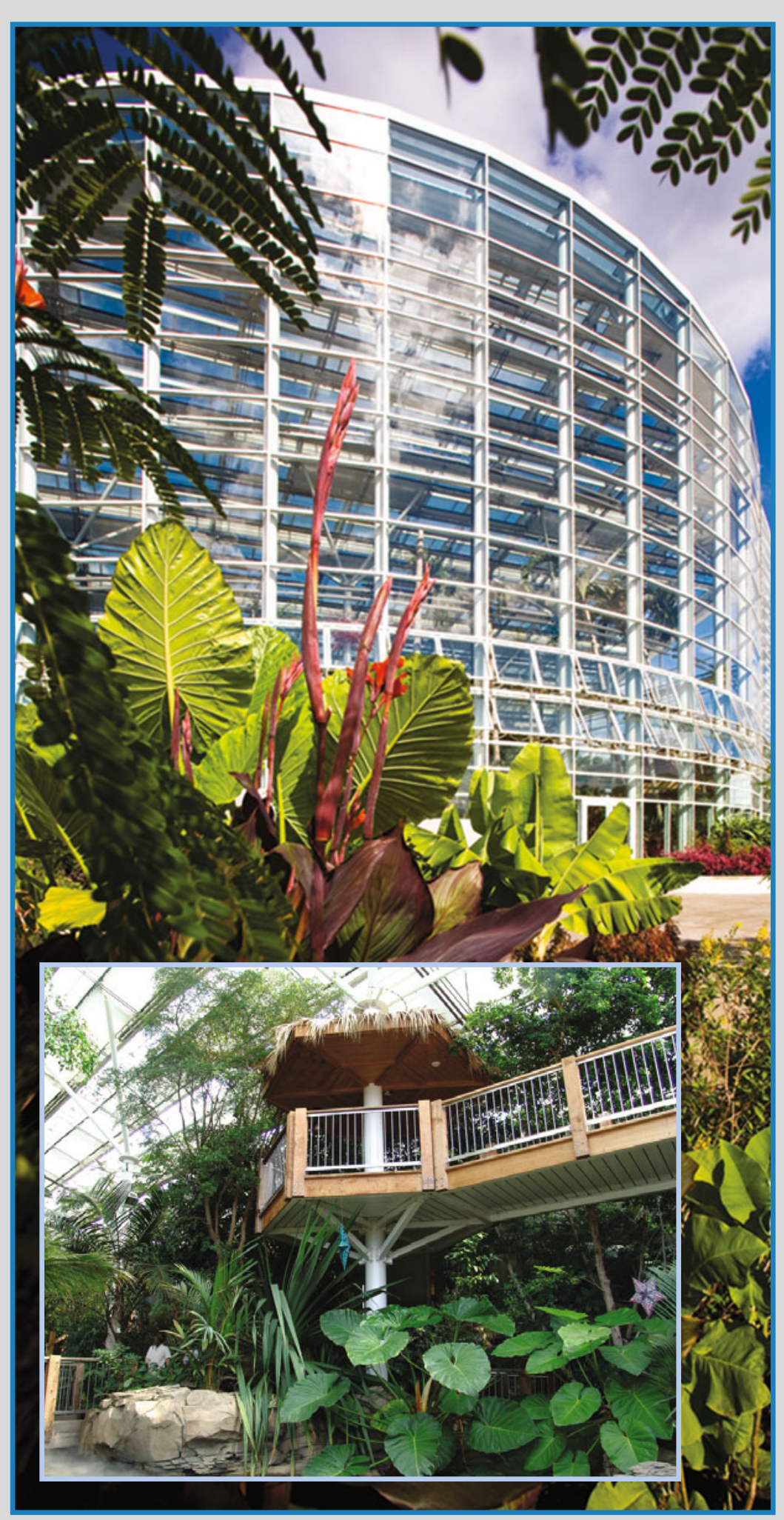

Figure 4. (Top): Phipps hit upon an unconventional building shape for its Tropical Forest Conservatory that permitted the use of insulated roof glass, while still maintaining light levels for growing plants. (Inset): Another radical change to conservatory design at the Tropical Forest is allowing half of the roof vents to be opened. This, combined with earth tube cooling and other innovations, has enabled the structure to be 100 percent passively cooled-essentially eliminating the "greenhouse effect" of the greenhouse.
Probably the most significant development for Phipps, though, had nothing to do with infrastructure. In 1993, Phipps changed its century-old relationship with the City of Pittsburgh by privatizing its operations. Piacentini was hired by the new board in 1994 to grow Phipps from a Pittsburgh landmark into a national treasure.

\section{LEARNING FROM LEED}

"At first, we really focused on the traditional botanical gardens way of doing things - great public programs, great collections, great guest amenities," said Piacentini. That changed when the Phipps organization interviewed William McDonough, considered one of the leading lights in the green building movement, as a potential architect for the Conservatory's expansion. Back in the 1990s, the concept of sustainable building was just starting to get off the ground, but Piacentini found McDonough's advocacy for it quite compelling. "He made it very clear how buildings account for a significant amount of energy waste, as well as water and air pollution," said Piacentini. "We had never thought of buildings in that way before." McDonough ultimately convinced Phipps to try for LEED certification on one building, the new Welcome Center. "LEED was still pretty new at that time, and there was some negativity around it. People were saying that we would never see any payback, that it was too expensive," said Piacentini. "It took some time to see how each of the requirements came into play and why they were requirements, but the more we started to understand the concepts behind the rating system, the more sense it made."

Administered by the U.S. Green Building Council, the LEED certification process rates buildings on a 100-point scale according to their management of environmental impact in a variety of indicators, including materials and resources, energy and atmosphere, site selection and management, and innovation in design. In trying to address these specific metrics with the Welcome Center, Piacentini said that his team was prompted to "start thinking about systems" and to begin to question traditional approaches to 


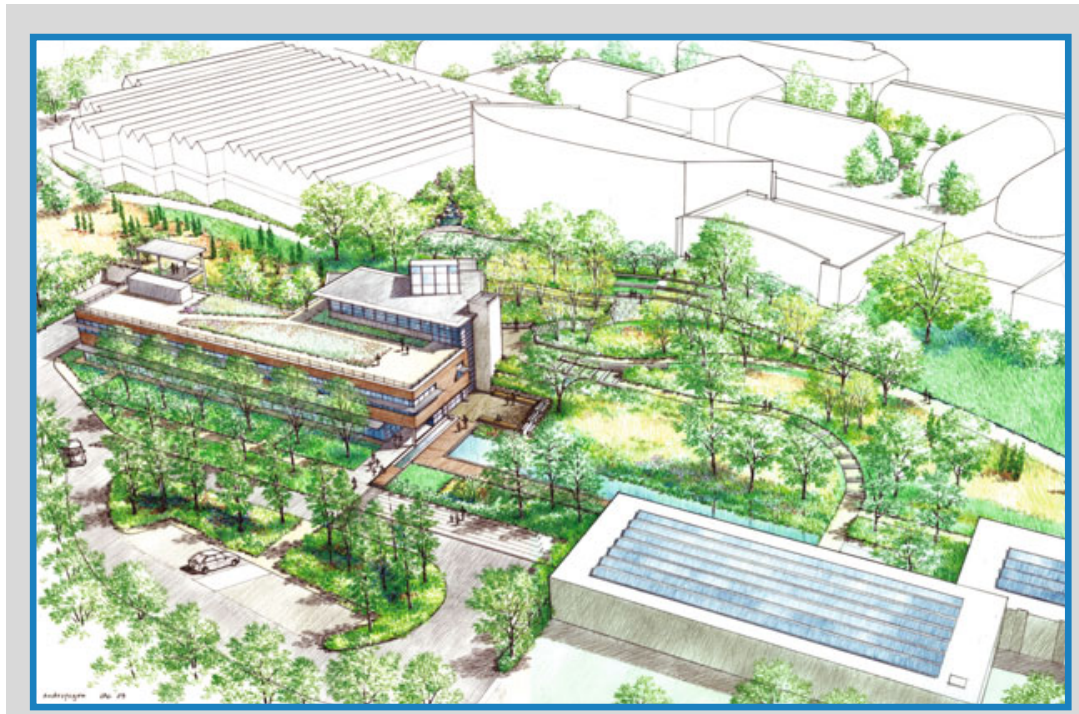

Figure 5. This aerial rendering of the CSL depicts many of the systems that have been incorporated into the campus for the purpose of achieving net-zero energy balance and net-zero water usage. (Credit: Andropogon Associates.)

building design. This led to a total retooling of the next major construction project in Phipps's expansion plan, a 12,000 square foot Tropical Forest Conservatory.

"Conservatory design hadn't really changed in over 160 years. It was still essentially building a big glass box," said Piacentini. By radically reconfinguring the building's mechanics to take better advantage of natural ventilation, strategically incorporating insulated roof glass, and using a solid oxide fuel cell as both a power and heat source, Phipps was able to reduce the cooling costs for the Tropical Forest to practically zero, and slashed heating costs to a fraction of what they would normally be for a conservatory of that size (Figure 4).

Then, immediately prior to the Tropical Forest's opening in 2006, Piacentini was introduced to the Living Building Challenge at that year's Greenbuild conference and the goal of "building the greenest building in the world" came into focus.

\section{INTEGRATIVE DESIGN UNLOCKS EFFICIENCIES}

The Living Building Challenge, issued by the International Living Future Institute, goes beyond LEED Platinum standards of efficiency to require that a structure prove, among 20 imperatives, net-zero energy balance and net-zero water usage, as well as deployment of sustainable, toxin-free materials. Rather than using LEED's approach of rating milestones achieved in construction, the Living Building Chal- lenge grants certification only after the building performs for a year, producing measurements documenting that the design has met the Challenge standards. Critical to the success of the Challenge is the "living" aspectlike an organism, every system in the building supports the others, while also interacting harmoniously with the surrounding environment.

"We were already thinking along the same lines as the concepts behind the Living Building Challenge," said Piacentini. "How does one process affect another? How does one building affect another on campus? How do all these things work together to impact the environment?" With the success of the LEED-certified Welcome Center and the energy-efficient design of the Tropical Forest behind them as proof of these concepts, the Phipps Board voted to accept the Living Building Challenge in 2007 as the driver for the final phase of its expansion plan (Figure 5).

If the building needed to be mod-

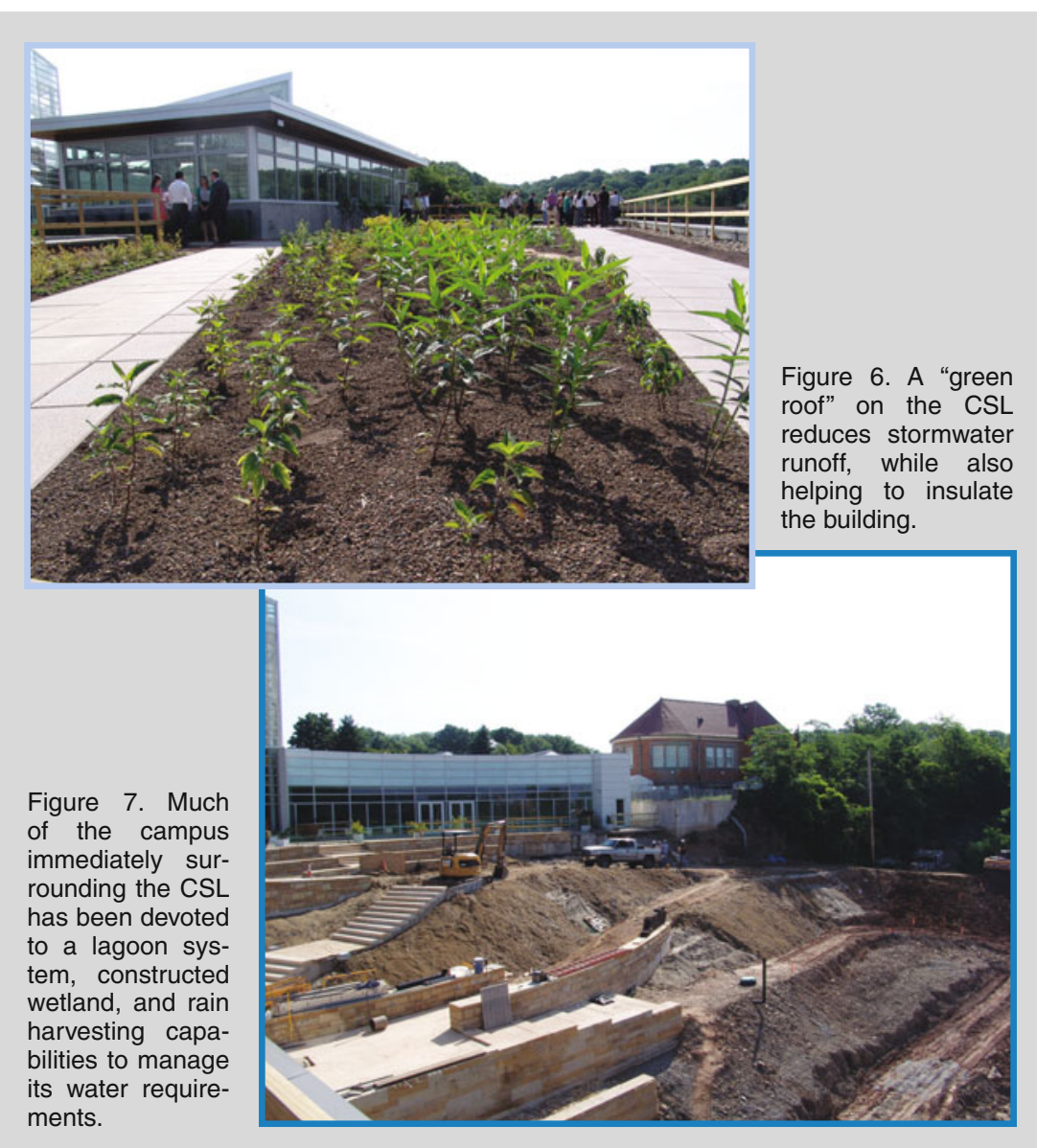


eled after a natural system in order to achieve the Challenge's high-performance goals (Figures 6, 7, 8), it seemed obvious to Piacentini that the people involved in designing, con- structing, and maintaining the CSL had to work just as synergistically. "I was convinced that the only way we were going to accomplish this was through an integrative design process," he said.

\section{COAXING A WORLD WATER SUPPLY FROM THE SUN}

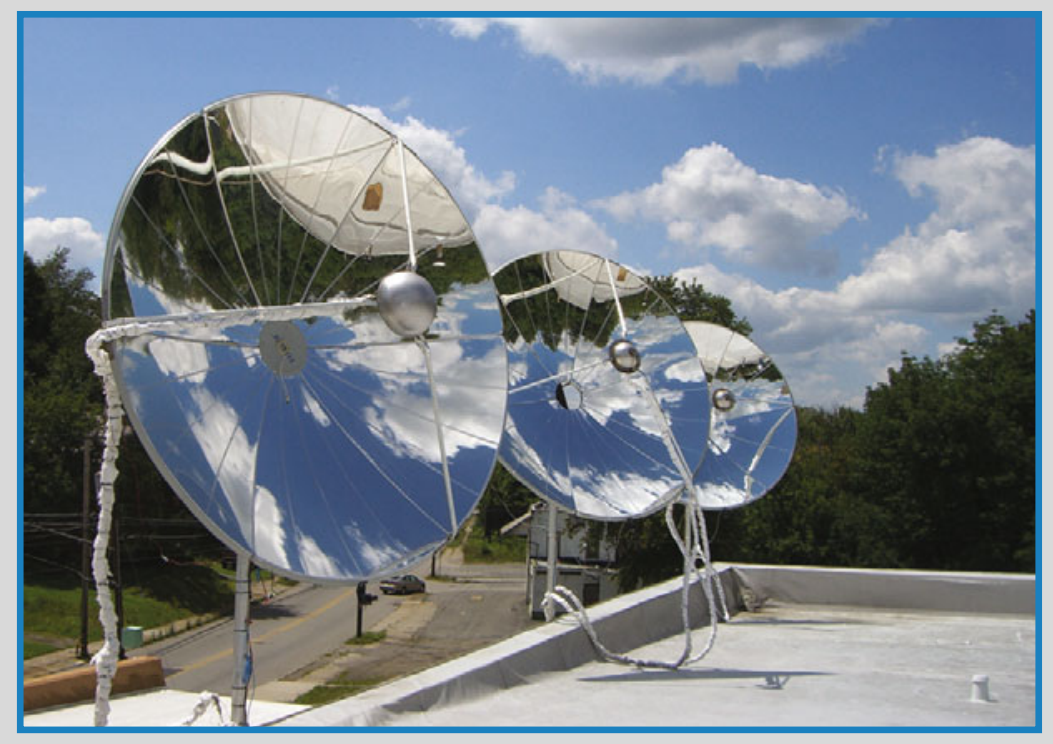

Inexpensive, 8-foot stamped steel satellite dishes make Epiphany's parabolic concentrator array easy to acquire, set up, and maintain in the remotest corners of the world. (Photo courtesy of Epiphany Solar Water Systems.)

One of the most stringent mandates of the Living Building Challenge is "net zero water," or total water independence. This means that the structure must harvest all precipitation, manage all stormwater runoff, and treat and re-use all waste water onsite.

An intricate system of lagoons, constructed wetlands, rain gardens, and a green roof enabled the Phipps CSL to reduce its waste water discharge drastically. Unique environmental conditions, however, still meant that a few hundred gallons a day had nowhere to go. Phipps then turned to a local engineer who has harnessed the power of the sun to bring fresh, clean water to the farthest and driest reaches of the world.

Tom Joseph, president and chief technology officer, Epiphany Solar Water Systems, New Castle, Pennsylvania, had at first been exploring concentrated solar power to generate electricity, but switched his focus to water purification when he became acquainted with UNICEF's projection that 2.5 billion people worldwide lack access to a safe water supply. "Electricity doesn't do you much good if you're dying of thirst," he said.

Joseph's system uses parabolic solar concentrators to convert sunlight to high intensity heat that vaporizes the water to be purified. The steam is then reconstituted to liquid form through a simple process that filters out contaminants and can remove salt from sea water. Phipps is using the Epiphany system to distill the CSL's excess discharge water and use it to water the Conservatory's orchid garden.

Since the people most at risk for a compromised water supply live in remote, developing regions, Joseph said that making his system easy to set up and maintain, with readily available materials, was critical.

For example, the parabolic solar concentrators are made from inexpensive, stamped steel satellite dishes lined with a coated, thermoformed plastic insert. Similar to the metalized coating used on automotive bumpers, the silvered material reflects approximately 94 percent of the sunlight back to the receiver domes. Also, unlike traditional larger-scale water purification systems, Joseph's does not require an external power supply to operate. "The components are commonly available in most parts of the world, and even if the exact materials aren't available, the processes used to make them are used by many other manufacturers, such as the automotive industry," said Joseph. "This means that we can make use of the global supply chains that are already in place."
Design and construction of buildings traditionally follow a linear process, with each engineer and designer focused on optimizing his or her component based on schematic designs drawn up independently by the architect and owner. An integrative design approach assembles the entire team from the beginning to establish performance targets and strategies for achieving them before "one line is drawn on paper or one CAD button is pushed," explained John Boecker of 7group/ Boecker Consulting Services.

Boecker had been tapped by Phipps to facilitate the project's charrette-an intense, collaborative process of developing solutions to the various challenges posed by the CSL. Boecker noted that most projects require at least five workshops during the charrette. Due to the complexity of the project imposed by the Living Building Challenge standards, Phipps held 14. "Every building project is unique, but Phipps was uniquely unique," he said.

The early focus of Phipps' charrette was ensuring that all team members were aligned around the purpose and goals, while also mapping an understanding of the interrealtionships among the various systems. Subsequent sessions incorporated energy modeling, lifecycle analysis, and other tools to reveal further patterns and interdependencies as part of an iterative process. Critical interactions between individual team members were identified within each workshop and assigned to be explored before the next session, with those ideas and discoveries brought to the entire team for discussion and analysis.

For the Phipps CSL project, the charrette process took about a year, with the latter two thirds of the workshops devoted to formulating conceptual ideas and homing in on a final design. Boecker said that in the integrative design timeline, the team generally begins developing schematic designs at about the time projects using traditional design processes have completed theirs. However, because the iterative work among all the team players occurs in the beginning of the design phase, the time needed to prepare the final construction documents 
is reduced by 25 to 30 percent.

More importantly, the solutions that have been identified generally work when they are implemented the first time. Boecker noted, for instance, that projects developed through integrative design tend to have up to 80 percent fewer construction change orders than average. "All the analysis and problem-solving, based on performance and cost, is done upfront with all the professionals who need to be involved in those decisions," he said. "Then, during construction, you can focus on the intent of that phase, rather than addressing issues of design and detail."

From a cost perspective, investing in the effort to capitalize on mutually beneficial interrelationships can lead to longer term savings by providing insights into where redundant systems can be downsized or even eliminated, said Boecker. In designing the CSL, materials frequently came into play as both enablers of and barriers to many of these approaches.

\section{MANAGING THE MATERIALS "RED LIST"}

Central to the Living Building Challenge is compliance with the "Red List"-an extensive inventory of chemicals, elements, and substances banned from use in any aspect of the building's construction because of their toxicity. "Many products that are traditionally used in construction contain these elements and finding alternatives can be time-consuming and, in some cases, seemingly impossible," said Chris Minnerly, principal, The Design Alliance Architects, who led the CSL design team charged with researching and specifying the building materials. "The building and manufacturing industries are only just beginning to respond to a new market of consumers that are concerned with the potential health risks to manufacturing and installing these materials in the spaces where we work and live. The Living Building Challenge aims to broaden the manufacturing market of healthy products to match the increase in consumer awareness. The market is not there yet."

Red List constraints are also not always obvious, sometimes emerging in unexpected applications, such as wood doors. "Once we received detailed information from the manufacturers, we realized we would have a problem finding a door that did not include some form of added formaldehyde in the glues for either the veneers or the core construction," Minnerly said. The team also quickly learned that because flyash contains trace amounts of mercury - a Red List element-many "sustainable" products made from recycled flyash could not be used, most notably carpeting.

Minnerly said that the process did allow for elements that are considered naturally occurring in products, citing cadmium in ceramic tile as an example. He also noted that the Living Building Challenge has had to make exemptions in instances where material alternatives do not yet exist.

Beyond working around the Red List materials when necessary, an added challenge was confirming exactly what went into making a number of products. "Many manufacturers are either reluctant to provide adequate information to evaluate the product against the Red List, or in some cases, do not have internal processes to obtain this information for our submittals in a timely and complete way," said Minnerly. "This can slow down decisions and risks holding up construction as the team works to resolve issues before committing to the purchase and installation of products. There was also

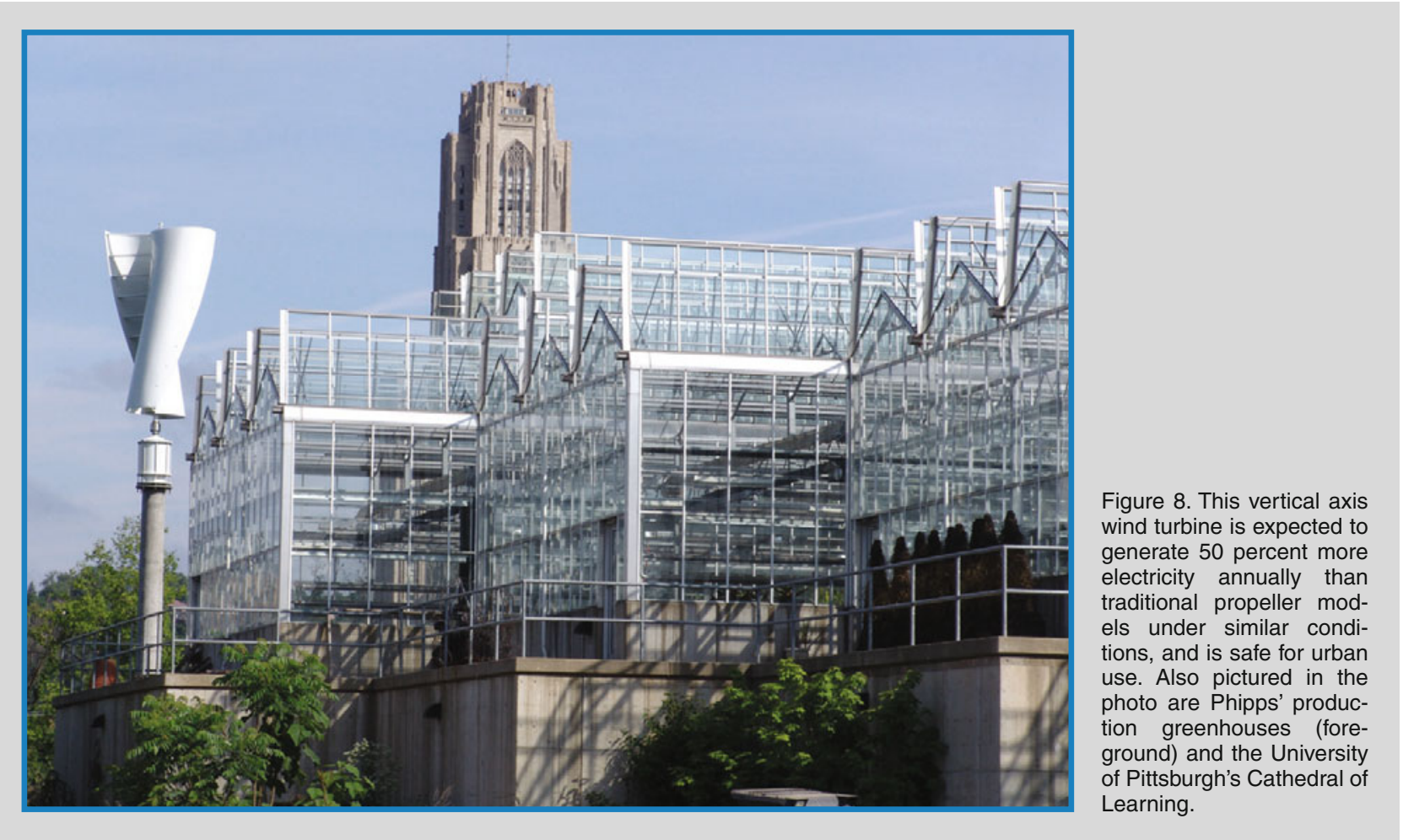


a learning process for manufacturers who assumed that their products would meet the Red List requirements because they were acceptable under LEED and considered environmentally friendly. Often this was not the case."

Compounding challenges posed by the Red List was the Living Building Challenge requirement that the majority of materials used in the CSL be harvested, extracted, or manufactured within a 500-mile radius. This quick- ly ruled out many "go to" rapidly renewable products for interior applications, such as cork flooring, typically extracted in Portugal, or Asian bamboo.

"Understandably, very few people are asking these questions right now. And, it's very time-consuming and costly for a manufacturer to research every single component of a product for an isolated instance or request," said Piacentini. "But as more organizations adopt the Living Building
Challenge or become aware of the Red List issues, manufacturers will have an incentive to change."

\section{MATERIAL APPLICATIONS THAT "TAKE THE HEAT"}

While the Living Building Challenge put tight constraints on what materials could be used and where they came from, it also opened the Phipps team to clever materials possibilities that reconciled sometimes competing functional and energy efficiency goals.

\section{PUSHING THE BOUNDARIES OF PV TECHNOLOGY}

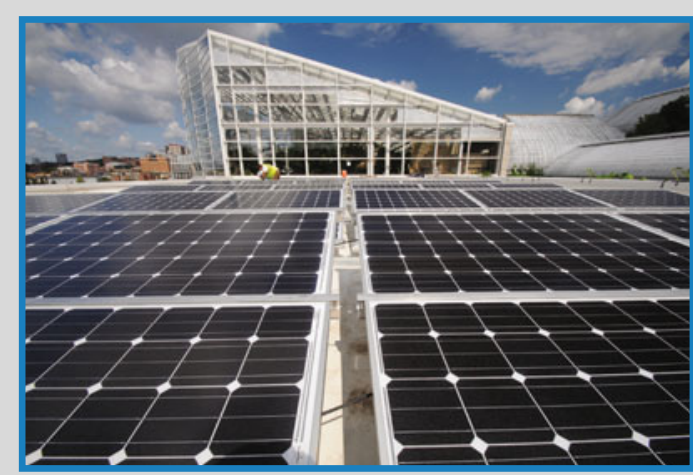

(Above): The CSL's photovoltaic array is the largest noncommmercial solar panel installation in the Pittsburgh area.

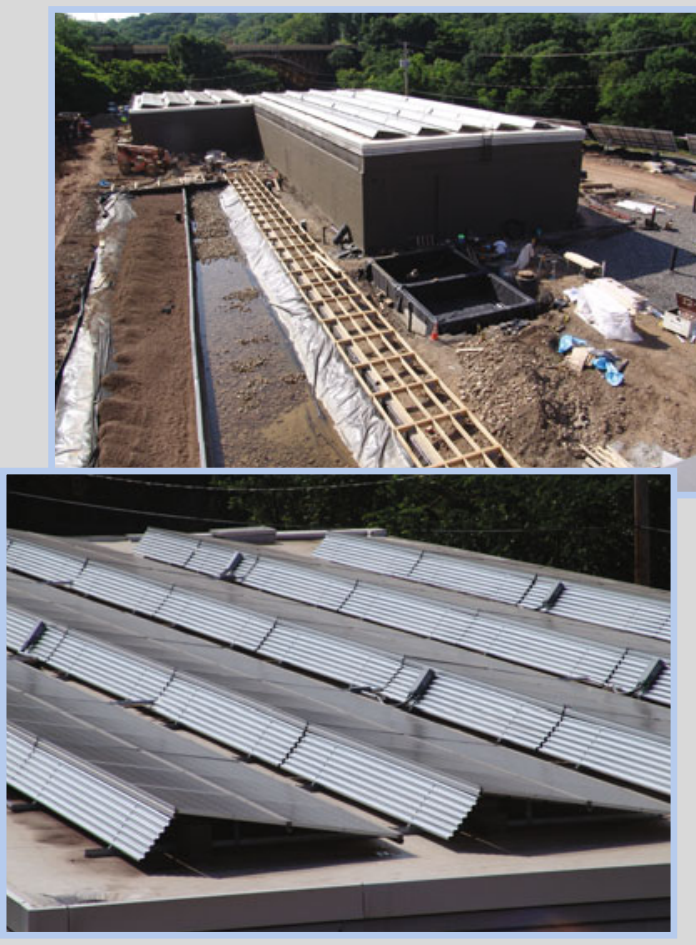

(Second and third photo): To operate efficiently in such a limited space, the CSL's solar installation was split into three major arrays, covering two separate buildings and a ground array on the edge of a hillside.
The primary source of electricity for the CSL is a robust solar photovoltaic (PV) installation. Piacentini noted that there is a misconception that PV technology "doesn't work" in Pittsburgh, due to strings of cloudy days and snowy winters. According to Joe Morinville, president, Energy Independent Solutions, McKees Rocks, Pennsylvania, the real challenges presented by the project had to do more with the restrictions placed on the CSL itself, rather than Pittsburgh's climate.

"Contrary to popular belief, solar still works in the snow and under the clouds, it just doesn't work as well," Morinville said. "In order to design our system to meet our required output targets, we needed to build a larger array than we would have if we were in Las Vegas or another sunny place, and we needed to use the pitch and orientation of the array that is best for Pittsburgh's micro climate."

In planning for the CSL's PV system, Morinville's company first had to contend with the limited amount of space available for the installation. "We were tasked to produce between 125,000 and $135,000 \mathrm{kWh} / \mathrm{yr}$, but had a very small footprint to work with," he said. Monocrystalline panels, which use the heart of the silicon ingot, were selected for the project since, according to Morinville, "They are typically more efficient than polycrystalline and thin films. With such a limited footprint, panel efficiency was critical."

Like so many other aspects of the CSL design and construction, it was the Living Building Challenge Red List that presented the greatest hurdles. Two core materials typically used in every array-PVC and galvanized metal - were specifically banned from use.

"We were able to switch our conduit to aluminum from PVC to meet the first restriction, but the galvanized metal was still a huge issue," said Morinville. "It's hard to find something strong enough and able to withstand the weather without using galvanization. Also, because of our site limitations, we needed racking solutions that could give us the high density of panels that we needed."

Morinville finally found a regional manufacturer, Flexrack in Youngstown, Ohio, that was able to build the racking by altering designs and materials types to satisfy both the Living Building Challenge mandates and the system's high panel density requirements.

"We have built other arrays similar in size and scope but nothing compares to the complexity of this project," said Morinville. "There is a huge learning curve when working with cutting-edge materials, equipment, and program guidelines. You may have done something 100 times, but when you have to do it with some brand new material, method or to a new standard, you have to be very flexible, be willing to relearn what you thought you were competent at, and be prepared to change designs many, many times in the process." 
For instance, because the CSL serves primarily as an office building, it needs to provide adequate interior lighting for work. And, as part of a botanical garden, it also needs to offer the right type of light for growing plants. However, the Living Building Challenge requires that electricity used for lighting be minimized in order to achieve net-zero energy balance. Designing the building to take advantage of as much natural daylight as possible solved part of the puzzle, but sunlight also creates heat, impacting on the efficiency of the environmental conditioning system.

Matching two different tripleglazed insulating glass units (IGUs) to different performance requirements within the building helped address these concerns, explained Piacentini. Both units use PPG Starphire ${ }^{\mathbb{R}}$ glass that contains about 10 percent of the iron content of regular glass. This composition enables the glass to remain clear and avoid the "greening" effect that sometimes occurs with thicker glass panels. The glass was then treated with low-emissivity (low-e) coatings to provide thermal control, while also allowing for the types of light required in different parts of the building.

The natural tendency of materials to "phase change" also provided the CSL's soaring, minimally conditioned atrium (Figure 9) with the requisite thermal mass for smoothing out daily temperature fluctuations and keeping the interior of the building comfortable all year. The specfic solution that Phipps used, BioPCM ${ }^{\mathrm{TM}}$, is attached over the insulation inside the walls and consists of mats implanted with a series of biomaterial-based cubes. When heat begins to build up in the building, the cubes melt to absorb the heat and cool the environment, and then solidify to release heat when the temperatures drop.

With these and numerous other efficiency-focused design decisions, Phipps estimates that it will be able to cut the annual energy usage of the CSL by at least 50 percent in comparison to a similar sized, traditionally designed building. This has also enabled Phipps to reduce the CSL's capacity requirements for its HVAC systems
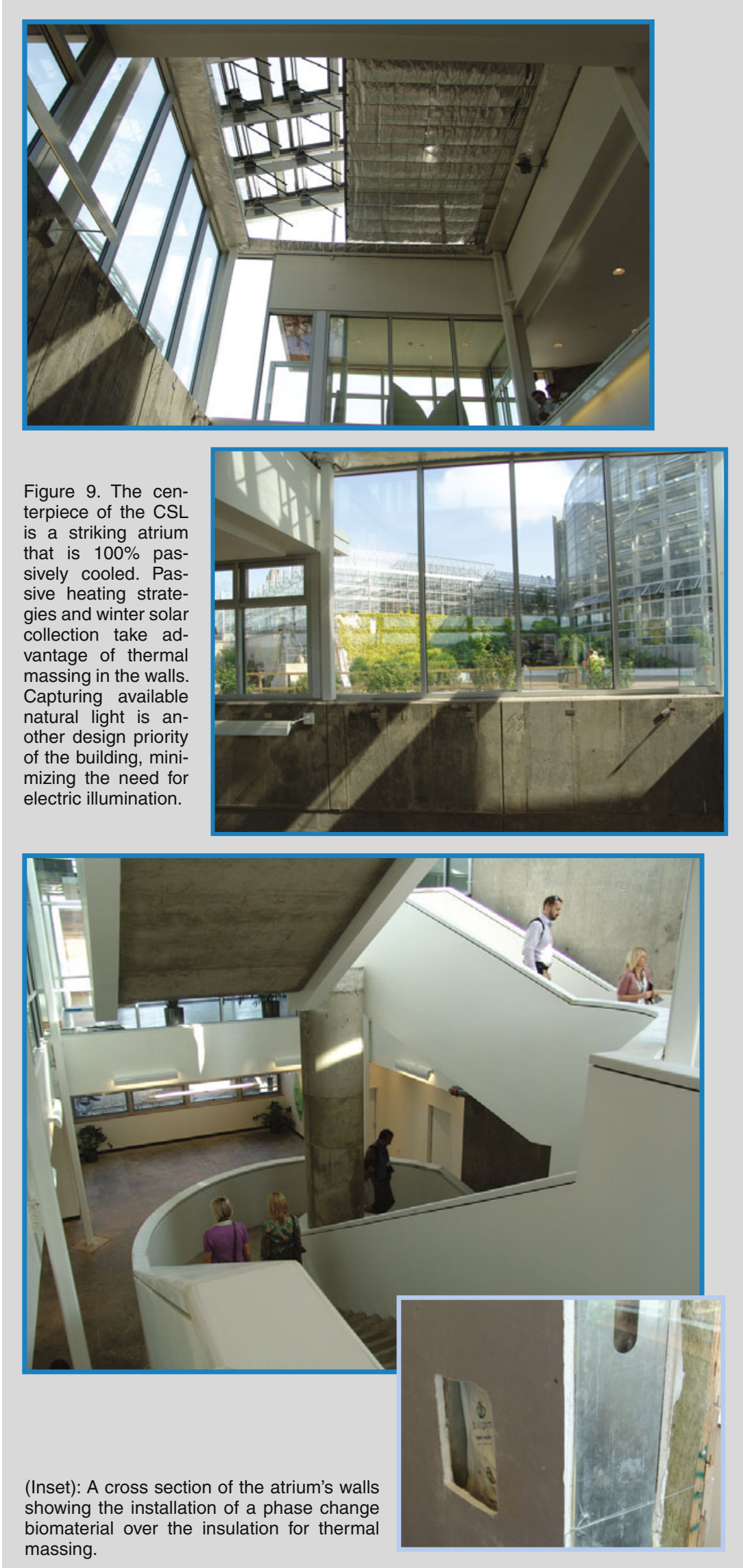
and associated infrastructure, such as pipes, ductwork, and pumps, by 30 to 40 percent.

\section{HOW THE CSL MEASURES UP}

In many ways, the real work on the CSL will begin once routine business army of sensors incorporated throughout the structure begins to collect data on its performance indicators. To help these readings turn out favorably, the CSL has evolved into a demonstration site for a number of approaches and technologies that are generally not deployed in an urban office complex. (See the accompanying sidebar articles for additional details.) In fact, the University of Pittsburgh and Carnegie Mellon University - both quite literally down the street from Phipps-will be using the building as a laboratory and test bed for long-term solutions in sustainable building.

However, Jason Wirick, Phipps director of Facilities and Sustainability,. noted that the human element interacting with these technologies could starts up inside its walls and the small

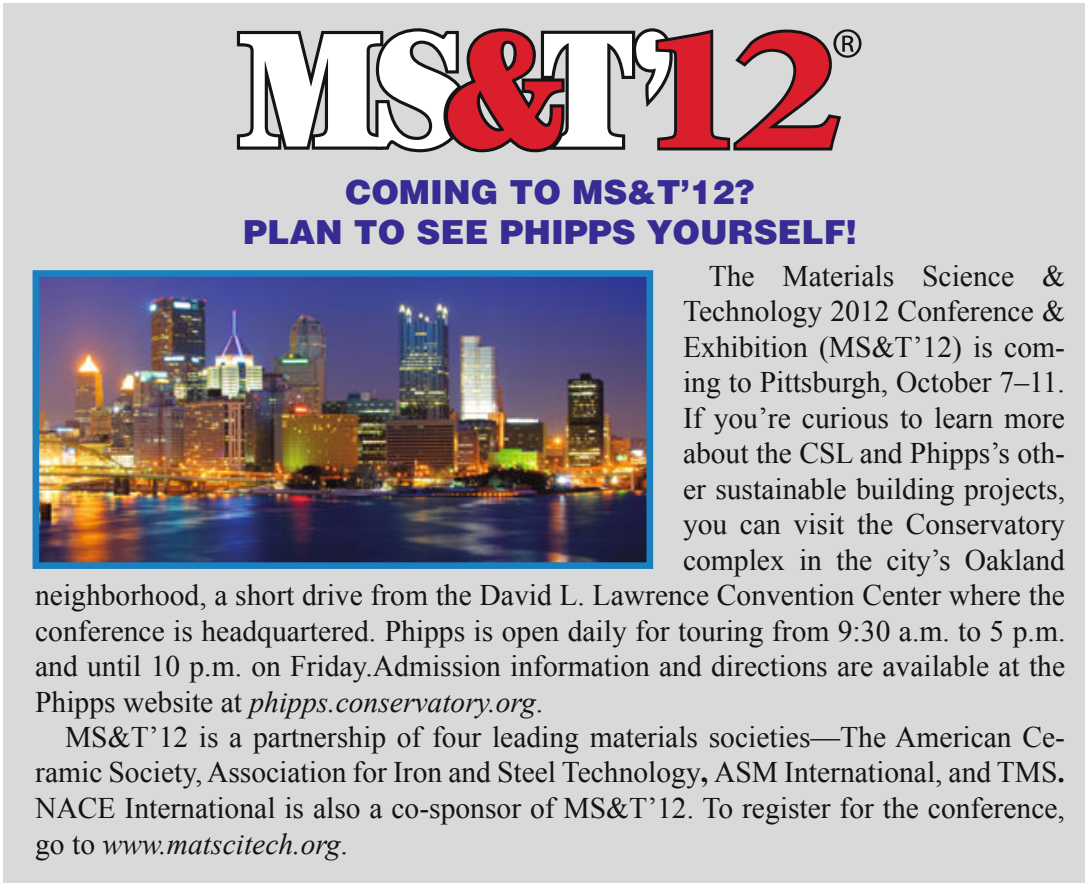

have the greatest impact of all on the CSL's performance goals. "Because of our stringent net-zero energy requirements, every kilowatt hour of energy used is critical," he said. "Engaging occupants on how their behav-

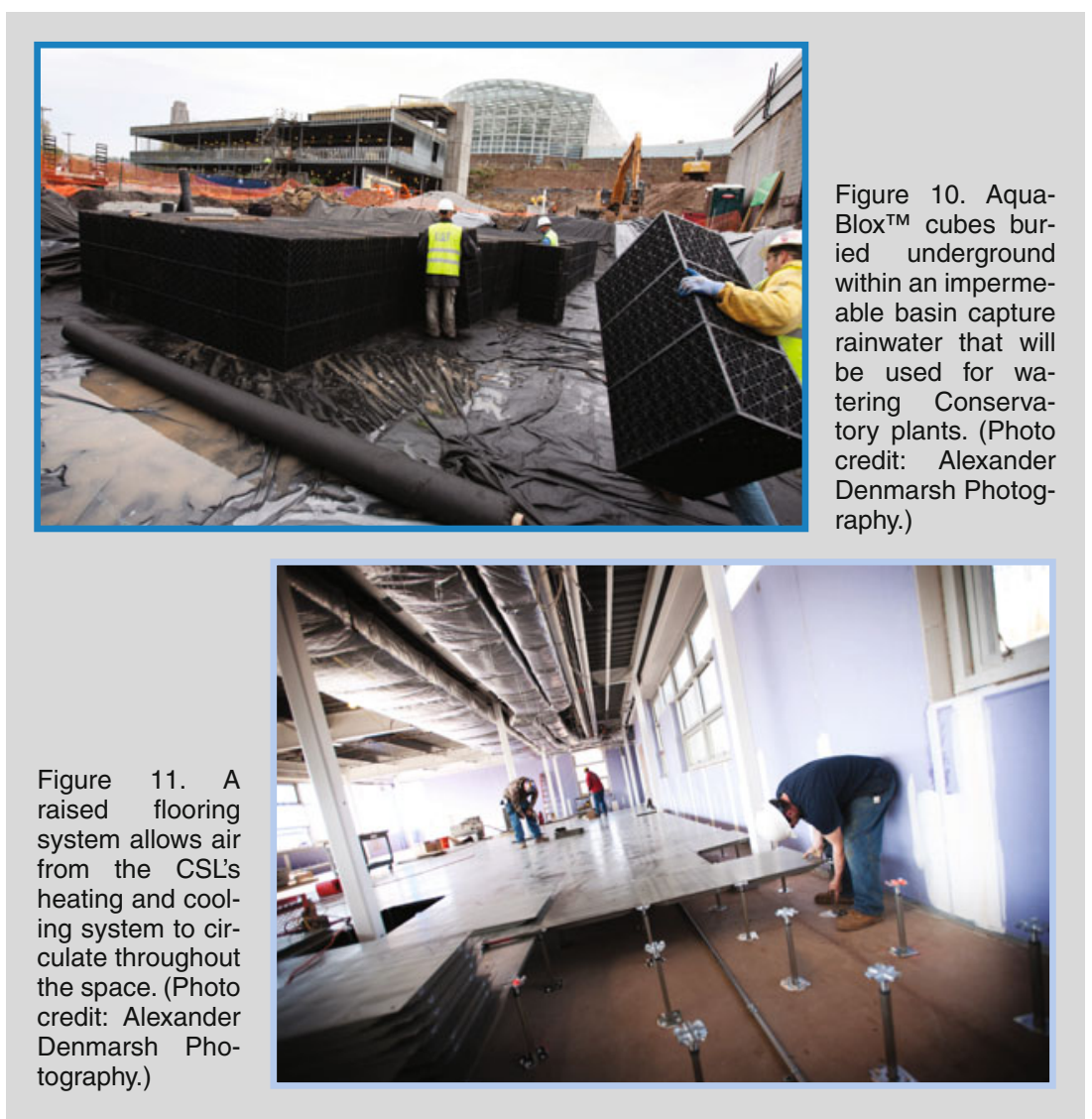

iors affect the building's performance will be an important aspect of operating this facility. The amount of metering will help us understand occupant behavior and the volume of real-time data will provide us an opportunity to study occupant trends. This will be very unique from a facilities management point of view compared to typical work environments."

Much of the CSL will also be open to the public, featuring displays of dashboards, models, and interpretive signage on how it was constructed and how all the systems are working together to achieve optimal performance.

"When visitors first walk in, they will probably be surprised to realize that it's an office building and that people are working there," said Piacentini. "Then, I believe they will be amazed at all the technology that is available that gives us the capacity to build high-performance buildings like this one (Figures 10, 11). My hope is that the experience will help them connect the dots as to how our interactions with the environment affects everything else and inspire them to make some changes in their own lives."

Lynne Robinson is a news and feature writer for TMS. Additional photographs by David Rasel, TMS media manager. 